\title{
Avian trait-mediated vulnerability to road traffic collisions
}

\author{
Sara M. Santos ${ }^{\mathrm{a}, \mathrm{b}, *}$, António Mira ${ }^{\mathrm{a}, \mathrm{b}}$, Pedro A. Salgueiro ${ }^{\mathrm{a}, \mathrm{b}}$, Pedro Costa ${ }^{\mathrm{a}, \mathrm{b}}$, Denis Medinas ${ }^{\mathrm{a}, \mathrm{b}}$, Pedro Beja ${ }^{\mathrm{c}, \mathrm{d}}$ \\ ${ }^{a}$ CIBIO/InBIO - Research Center in Biodiversity and Genetic Resources, Pólo de Évora, Universidade de Évora, Departamento de Biologia, Mitra, 7002-554 Évora, Portugal \\ b UBC - Conservation Biology Unit, Universidade de Évora, Departamento de Biologia, Mitra, 7002-554 Évora, Portugal

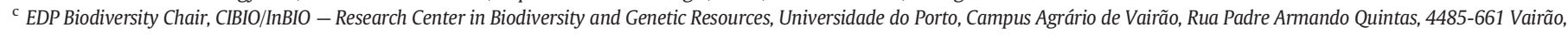 \\ Portugal \\ d CEABN/InBIO, Centro de Ecologia Aplicada “Professor Baeta Neves”, Instituto Superior de Agronomia, Universidade de Lisboa, Tapada da Ajuda, $1349-017$ Lisboa, Portugal
}

\section{A R T I C L E I N F O}

\section{Article history:}

Received 11 November 2015

Received in revised form 31 May 2016

Accepted 6 June 2016

Available online $\mathrm{xxxx}$

\section{Keywords:}

Anthropogenic mortality

Bird ecology

Foraging behaviour

Manly's index

Road collisions

Species traits

\begin{abstract}
A B S T R A C T
Collision with vehicles is an important source of bird mortality, but it is uncertain why some species are killed more often than others. Focusing on passerines, we tested whether mortality is associated with bird abundances, and with traits reflecting flight manoeuvrability, habitat, diet, and foraging and social behaviours. We also tested whether the species most vulnerable to road-killing were scarcer near $(<500 \mathrm{~m})$ or far $(>500-5000 \mathrm{~m})$ from roads. During the breeding seasons of 2009-2011, we surveyed roadkills daily along $50 \mathrm{~km}$ of roads, and estimated bird abundances from 74 point counts. After correcting for phylogenetic relatedness, there was strong correlation between roadkill numbers and the abundances of 28 species counted near roads. However, selectivity indices indicated that Blue tit (Parus caeruleus), Blackcap (Sylvia atricapilla) and European goldfinch (Carduelis carduelis) were significantly more road-killed than expected from their abundances, while the inverse was found for seven species. Using phylogenetic generalised estimating equations, we found that selectivity indexes were strongly related to foraging behaviour and habitat type, and weakly so to body size, wing load, diet and social behaviour. The most vulnerable passerines were foliage/bark and swoop foragers, inhabiting woodlands, with small body size and low wing load. The species most vulnerable to road collisions were not scarcer close to roads. Overall, our study suggests that traits provide a basis to identify the passerine species most vulnerable to road collisions, which may be priority targets for future research on the population-level effects of roadkills.
\end{abstract}

(C) 2016 Elsevier Ltd. All rights reserved.

\section{Introduction}

Roads may have negative impacts on wildlife (Spellerberg, 1998; Fahrig and Rytwinski, 2009; Benítez-López et al., 2010), mainly due to habitat fragmentation and road-related mortality (i.e., roadkills) (Pons, 2000; Erritzoe et al., 2003; Barthelmess and Brooks, 2010; van der Ree et al., 2015). Collisions with vehicles can be particularly detrimental, because hundreds of millions of individuals are killed each year, though the effects of this mortality on the long term persistence of the species most affected are still uncertain (Kociolek et al., 2011; Roger et al., 2011; Borda-de-Água et al., 2014; Loss et al., 2015). Therefore, impact assessment and mitigation should be based on a thorough understanding of the species most vulnerable to road mortality, which is generally very limited (Kociolek et al., 2011).

\footnotetext{
* Corresponding author at: CIBIO/InBIO - Research Center in Biodiversity and Genetic Resources, Pólo de Évora, Universidade de Évora, Departamento de Biologia, Mitra, 7002-554 Évora, Portugal.

E-mail addresses: saramlsantos@yahoo.com (S.M. Santos), amira@uevora.pt (A. Mira), pas@uevora.pt (P.A. Salgueiro), pedrocostabio@hotmail.com (P. Costa), denimedinas@gmail.com (D. Medinas), pbeja@cibio.up.pt (P. Beja).
}

Birds are often killed due to collisions with vehicles (Erritzoe et al., 2003; Summers et al., 2011; Loss et al., 2015), with roadkills representing up to $5 \%-10 \%$ of overall bird mortality in the Western Paleartic (Møller et al., 2011). Many species are affected, with passerines and owls being among the most commonly reported groups (Erritzoe et al., 2003; Benítez-López et al., 2010; Boves and Belthoff, 2012). However, there is great disparity among studies regarding the number and species killed at different sites, or at the same site over time, though reasons for this are not always clear. One possibility is that the number of road-killed individuals is mainly a consequence of bird abundances near roads, because more individuals of common species are likely to be exposed to collision risk than those of rare species. This idea implies that most collisions should involve species that are naturally abundant in habitats bordering roads (Møller et al., 2011; D'Amico et al., 2015), or species that are attracted by resources provided directly or indirectly by roads such as food, hunting perches, or nesting places (Barrientos and Bolonio, 2009; Morelli et al., 2014; Ascensão et al., 2015). It is possible, however, that road mortality risk is also affected by bird traits, with some species being killed more (or less) frequently than expected from their abundances (Erritzoe et al., 2003; Møller et al., 2011; Cook and Blumstein, 2013). This selective mortality might be important, as it could induce long term changes in bird 